Article

\title{
Damage Imaging in Lamb Wave-Based Inspection of Adhesive Joints
}

\author{
Magdalena Rucka * (D), Erwin Wojtczak and Jacek Lachowicz \\ Department of Mechanics of Materials and Structures, Faculty of Civil and Environmental Engineering, Gdansk \\ University of Technology, Narutowicza 11/12, 80-233 Gdansk, Poland; erwin.wojtczak@pg.edu.pl (E.W.); \\ jacek.lachowicz@pg.edu.pl (J.L.) \\ * Correspondence: magdalena.rucka@pg.edu.pl or mrucka@pg.edu.pl; Tel.: +48-58-347-2497
}

Received: 5 February 2018; Accepted: 27 March 2018; Published: 29 March 2018

\begin{abstract}
Adhesive bonding has become increasingly important in many industries. Non-destructive inspection of adhesive joints is essential for the condition assessment and maintenance of a structure containing such joints. The aim of this paper was the experimental investigation of the damage identification of a single lap adhesive joint of metal plate-like structures. Nine joints with different defects in the form of partial debonding were considered. The inspection was based on ultrasonic guided wave propagation. The Lamb waves were excited at one point of the analyzed specimen by means of a piezoelectric actuator, while the guided wave field was measured with the use of a laser vibrometer. For damage imaging, the recorded out-of-plane vibrations were processed by means of the weighted root mean square (WRMS). The influence of different WRMS parameters (i.e., the time window and weighting factor), as well as excitation frequencies, were analyzed using statistical analysis. The results showed that two-dimensional representations of WRMS values allowed for the identification of the presence of actual defects in the adhesive film and determined their geometry.
\end{abstract}

Keywords: adhesive joint; single lap joint; non-destructive testing; damage identification; Lamb waves; scanning laser vibrometry

\section{Introduction}

Adhesive joints of metal elements are a kind of non-separable connections with numerous applications, e.g., in the aviation, machine, or automotive industry [1]. The strength and durability of adhesive joints are essential for the safety of engineering structures. They are highly susceptible to any defects resulting from mistakes that were committed during the preparation and joining of elements, e.g., poor condition of the adherend surface or a lack of glue on a part of the overlay. Additionally, a gradual deterioration in the quality of the adhesive material cannot be neglected. Typical adhesive joints are not capable of being inspected based on visual techniques as the place of damage occurrence (the adhesive film) is hidden between the joined parts. Destructive testing provides very accurate results [1]. This approach allows for the determination of the influence of certain parameters (e.g., damage existence [2,3] or adhesion condition [4]) on the strength of representative samples, which were usually prepared in laboratory conditions and to predict the state of existing joints. Destructive testing is not free of disadvantages, it is, in general, a high-cost solution and cannot usually be applied to existing structures. Therefore, different non-destructive testing (NDT) methods have been adopted for the inspection of adhesive joints [5] including ultrasonics [6,7], thermography [8], radiography [7], digital image correlation [9,10], or electromechanical impedance spectroscopy [11].

In recent years, one of the most promising techniques for damage assessment is the use of guided wave propagation (e.g., [12-14]). Lamb waves are a specific type of guided wave that occur in a media that is restrained by two parallel surfaces, e.g., thin plate-like structures. The ability of Lamb waves to 
interact with any kind of defect makes them particularly useful in the diagnostics of various elements of engineering structures, including adhesive joints. In previous studies, guided waves have been proven to be an effective technique for the inspection of adhesive lap joints [15-18], adhesive bonds between composites [19-21], adhesive butt joins of plates [22], or the detectability of the adhesion level [23].

In the guided wave propagation technique, the wave is usually excited at one point of a structure and is collected at a number of points that are spread over the whole structure. In general, two measurement strategies can be used. The first method depends on using a small number of ultrasonic or piezoelectric transducers, followed by an analysis of registered time histories. This strategy is mainly used for structural health monitoring (SHM). Another approach is directed towards non-contact techniques, such as scanning laser Doppler vibrometry (SLDV) and the sensing of the full guided wave field (e.g., [24-26]). This strategy is more appropriate for quality assurance testing and periodic nondestructive inspection. Particular signals that are registered at numerous points distributed over a monitored area provide a two-dimensional representation of propagating waves at specific time instances. If any damage exists in an analyzed structure, a disturbance in the wavefront shape can be observed. The perturbation is more or less clearly visible depending on the type, size, and position of the defect. This visual assessment of SLDV maps allows for one to determine the presence of damage, but does not give a clear image due to the multiple reflections of waves from discontinuities and element edges [25]. The determination of the actual shape and size of the existing defect requires additional processing and damage imaging [27-29]. One of the simplest but most efficient techniques is based on vibration energy distribution and utilizes the calculation of a root mean square (RMS). This method was improved to be more applicable for damage detection by defining the weighted root mean square (WRMS) method [30]. Recently, the RMS has been successfully used in various damage detection applications [25,26,31-36]. Żak et al. [30] investigated aluminum and composite plates as well as composite elements of a helicopter, all with the damage being simulated by an additional mass. They concluded that better resolution in WRMS maps corresponded to higher values of the weighting factor (linear or square). Localization of damaged rivets in a stiffened plate structure based on RMS maps was conducted by Radzieński et al. [31] where the authors used a five-cycle burst of different frequencies $(5 \mathrm{kHz}, 35 \mathrm{kHz}$, and $100 \mathrm{kHz})$. The best results were obtained in the case of an excitation signal of $100 \mathrm{kHz}$, where the wavelength was shorter than the distance between two rivets. Lee and Park [32] considered an aluminum plate with notches of various orientation (tangential, perpendicular, and diagonal to the incident wave front). Based on RMS images, only tangential damage was successfully detected without a comparison to the intact images. Saravanan et al. [33] used radially weighted and factored RMS for damage localization in an aluminum plate. Detection of delamination in a composite T-joint using RMS images was studied by Geetha et al. [34]. Marks et al. [35] presented experimental investigations on the detection of disbonds in a stiffened panel based on the RMS plots. Wave packets with three different frequencies, namely $100 \mathrm{kHz}, 250 \mathrm{kHz}$, and $300 \mathrm{kHz}$, were applied. The authors concluded that the excitation frequency is an important consideration for the inspection of disbonds. In the conducted works, only higher frequencies $(250 \mathrm{kHz}$ and $300 \mathrm{kHz})$ were able to detect damage. Lee et al. [36] applied the WRMS to localize the notches and corrosion areas in aluminum plates and chose 2 as the weighting parameter. Kudela et al. [25] studied the detection of delamination in a composite plate using WRMS with the weighting factor set as 2.7. They also proposed a selective WRMS that enabled the elimination of edge reflections. Detection of disbond inserts in composite elements was performed by Pieczonka et al. [26] using RMS and three-dimensional (3D) scanning. In the conducted experimental investigations, it was noticed that in-plane RMS maps provided a better indication of damage than out-of-plane RMS maps. Summarizing all of the works that are reported above, the main problem that is connected with damage imaging using WRMS is the fact that the weighting factor is set arbitrary with no clear explanation for the choice of a specific value.

This study presents an approach to the damage identification of adhesively bonded joints that is based on the Lamb wave propagation. The guided wave field was measured with the use of scanning 
laser Doppler vibrometry and then processed by means of the weighted root mean square. The object of the research was a single lap adhesive joint of metal plate-like structures. To verify the feasibility of the proposed approach, nine specimens with defects that were differing in size and position were tested. The influences of different WRMS parameters (i.e., the time window and weighting factor), as well as excitation frequencies, were analyzed. A novel element in this research was the application of the statistical analysis in determining the WRMS parameters. It has been proven that the obtained WRMS maps of damaged joints were characterized by bimodal distributions that created the opportunity to determine the optimal value of the time window, weighting factor, and excitation frequency.

\section{Materials and Methods}

\subsection{Description of Specimens}

The object of the research was a single lap adhesive joint of steel plates. Dimensions of each adherend were $270 \mathrm{~mm} \times 120 \mathrm{~mm} \times 3 \mathrm{~mm}$. The length of the overlap was $60 \mathrm{~mm}$ (the half-width of the plate). The geometry of the analyzed joint is shown in Figure 1. The plates were degreased with Loctite-7063 cleaner and dried. Then, the surface of the overlap was treated with abrasive paper (type P120) and was degreased again just before applying the glue. The adhesive layer was prepared with the use of the epoxy-based glue Loctite EA 9461. The mean value of the bondline thickness for all of the specimens was equal to $0.216 \mathrm{~mm}$ and the standard deviation had a value of $0.043 \mathrm{~mm}$, which resulted in the coefficient of variation being equal to 0.198 .

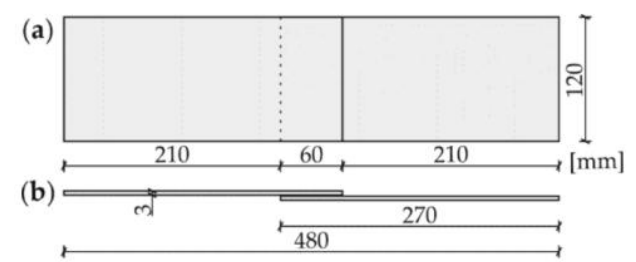

Figure 1. Geometry of the analyzed single lap joint: (a) plan view; and, (b) side view.

Investigations were conducted for nine types of specimens (Figure 2): one intact (\#1) and eight (\#2-\#9) with different defects in the form of partial debonding. The defects were modelled as a lack of glue on a part of the overlap surface. A PTFE tape of $0.2 \mathrm{~mm}$ thickness was used to prevent the glue from leaking to the debonding areas of the damaged joints. The adherends of each specimen were separated after the experimental measurements to determine the exact geometry of defects in the prepared joints. Photographs of the disconnected joints are presented in Figure 3.

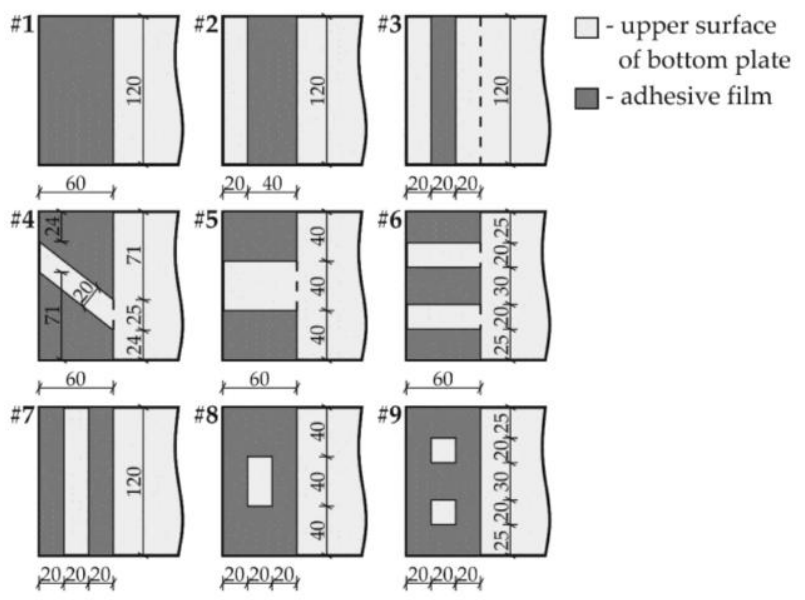

Figure 2. Investigated specimens: intact (\#1) and with defects (\#2-\#9). 

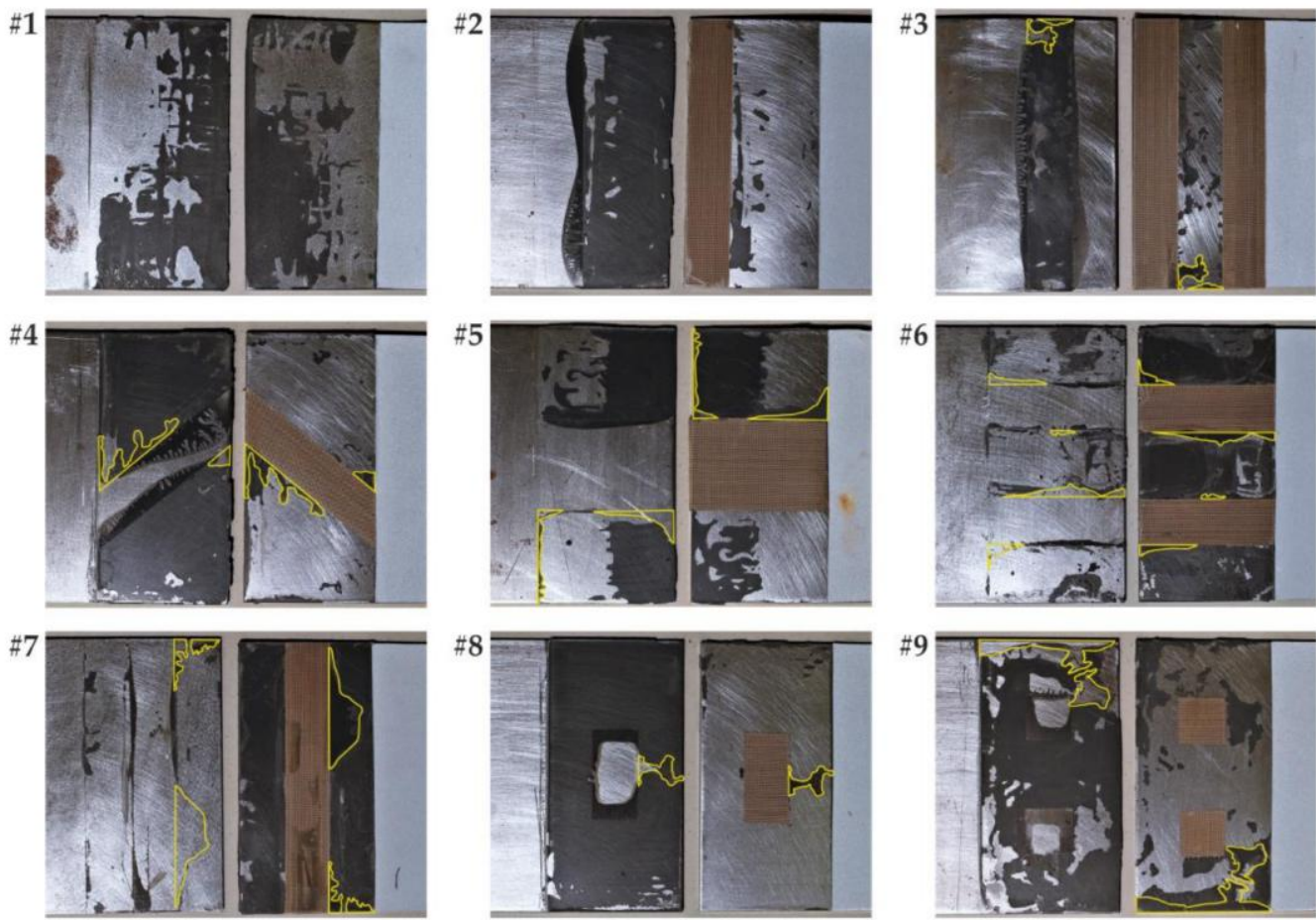

Figure 3. Photographs of the investigated specimens after separation (regions outlined with yellow line denote kissing defects).

It is visible in Figure 3 that the defects had slightly different shapes and areas than was assumed. The glue that leaked onto the surfaces covered with the PTFE tape (i.e., intended voids) did not affect the WRMS results because the tape prevented the plates from connecting even though there were some adhesive leakages. However, in addition to the intended voids, some additional areas resulting from the improper adhesion of the adhesive to the adherend (so-called kissing defects or low volume defects [8]) were identified for specimens \#3 to \#9. The kissing defect regions are outlined in Figure 3 by the yellow line. To quantify the real defect areas, including both the intended voids and kissing defects, the photographs seen in Figure 3 were processed using the ImageJ program [37]. The results are given in Table 1.

Table 1. Designed and determined area of defects.

\begin{tabular}{ccccc}
\hline No. of Sample & $\begin{array}{c}\text { Design Surface of } \\
\left.\text { Defect Area } \mathbf{( c m}^{\mathbf{2}}\right)\end{array}$ & $\begin{array}{c}\text { Determined Surface of } \\
\text { Defect Area Including } \\
\left.\text { Kissing Defects } \mathbf{( c m}^{\mathbf{2}}\right)\end{array}$ & $\begin{array}{c}\text { Design Relative } \\
\text { Defect Surface (\%) }\end{array}$ & $\begin{array}{c}\text { Determined } \\
\text { Relative } \\
\text { Defect Surface (\%) }\end{array}$ \\
\hline$\# 1$ & - & - & - & - \\
$\# 2$ & 24.00 & 24.00 & $33.33 \%$ & $33.33 \%$ \\
$\# 3$ & 48.00 & 49.11 & $66.67 \%$ & $68.21 \%$ \\
$\# 4$ & 15.00 & 17.64 & $20.83 \%$ & $24.50 \%$ \\
$\# 5$ & 24.00 & 26.03 & $33.33 \%$ & $36.16 \%$ \\
$\# 6$ & 24.00 & 26.33 & $33.33 \%$ & $36.57 \%$ \\
$\# 7$ & 24.00 & 9.55 & $33.33 \%$ & $41.05 \%$ \\
$\# 8$ & 8.00 & 13.34 & $11.11 \%$ & $12.63 \%$ \\
$\# 9$ & 8.00 & & $11.11 \%$ & $18.53 \%$ \\
\hline
\end{tabular}

\subsection{Experimental Setup}

Experimental measurements consisted of the excitation of Lamb waves in the lower adherend and the collection of wave propagation signals in the selected area of the specimen. The experimental setup is presented in Figure 4. The excitation signal was generated by means of the arbitrary function generator AFG 3022 (Tektronix, Inc., Beaverton, OR, USA) and the high-voltage amplifier PPA 2000 
(EC Electronics, Krakow, Poland). Lamb waves were excited by the plate piezoelectric actuator NAC2024 (Noliac, Kvistgaard, Denmark), with dimensions of $3 \times 3 \times 3 \mathrm{~mm}^{3}$ and a resonant frequency of over $500 \mathrm{kHz}$. The actuator was bonded to the bottom side of the specimen (Figure $4 \mathrm{~b}$ ) using petro wax 080A109 (PCB Piezotronics, Inc., Depew, NY, USA). The excitation signal was a five-peak wave packet obtained from a sinusoidal burst with a carrier frequency of $200 \mathrm{kHz}$ modulated by the Hanning window. There were also additional excitation signals for specimens \#3 and \#6 that differed in the frequency value from the basic variant $(100 \mathrm{kHz}$ and $50 \mathrm{kHz}$, instead of $200 \mathrm{kHz})$. Acquisition of the wave propagation signals was realized by the scanning head of the laser vibrometer PSV-3D-400-M (Polytec GmbH, Berlin, Germany) with a VD-09 velocity decoder (Figure 4a). Time signals were acquired with a sampling frequency of $2.56 \mathrm{MHz}$ and were averaged 40 times to improve the signal-to-noise ratio. The excitation signal was triggered as external and monitored using a reference channel of the vibrometer. To improve the backscatter of light, the scanned surface was covered with retro-reflective sheeting. Velocity values (out-of-plane components) were recorded in the time domain in 7381 points that were distributed at the top side of the specimen (on the surface of the upper plate with no PTFE tape attached, see Figure 3). The area was scanned point by point in the mesh of 61 rows and 121 columns (Figure 5), giving a scan resolution of $1.933 \mathrm{~mm}$ and about nine scan points per the shortest wavelength. Signals sensed at all of the points allowed for us to prepare a map of the propagating waves, i.e., a two-dimensional plane view at a specific time instance.

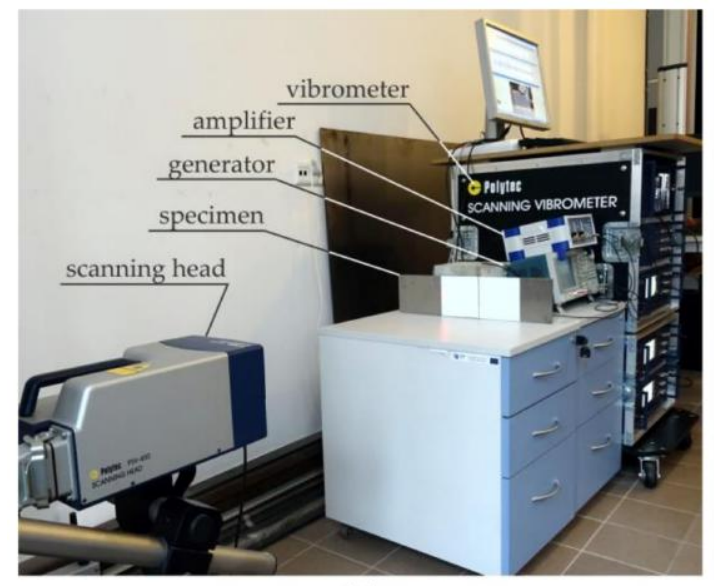

(a)

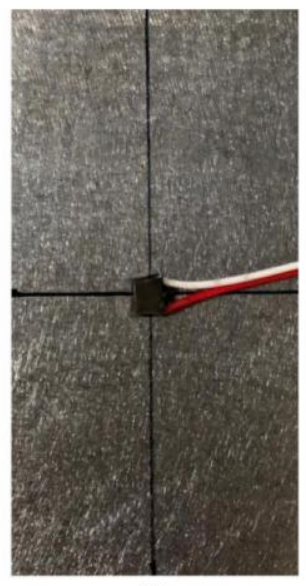

(b)

Figure 4. Experimental setup: (a) instrumentation for generation and acquisition of Lamb waves; and, (b) detail showing the piezo actuator attached to the specimen.

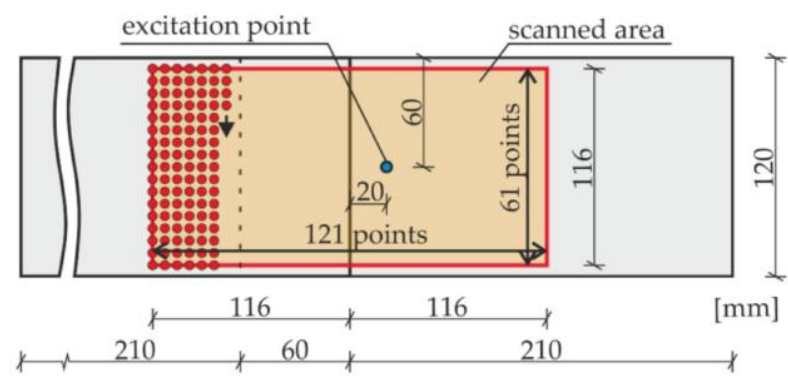

Figure 5. Investigated specimen with indicated scanning points.

\subsection{Weighted Root Mean Square Damage Imaging}

The guided wave field that was acquired with the use of SLDV can be further processed to more accurately identify the position and shape of defects. This processing technique depends on the 
calculation of the weighted root mean square for each registered time signal and the creation of a damage map. The WRMS for a time signal $s(t)$ can be defined as follows $[25,26,30,33,36]$

$$
W R M S=\sqrt{\frac{1}{t_{2}-t_{1}} \int_{t_{1}}^{t_{2}}\left(w(t) s(t)^{2}\right) d t}
$$

where $w(t)$ denotes a weighting factor and $\left(t_{2}-t_{1}\right)$ is length of the time window with $t_{1}$ denoting the beginning of the time window and $t_{2}$ denoting the end of the time window. For a discrete signal $s_{r}=s\left(t_{r}\right)$ sampled with $\Delta t$ interval and calculated from the interval $T=(N-1) \Delta t=t_{2}-t_{1}$, the WRMS can be approximated by

$$
W R M S=\sqrt{\frac{1}{N} \sum_{r=1}^{N}\left(w_{r} s_{r}^{2}\right)}
$$

where $N$ is the number of samples in the signal used for RMS calculation and $w_{r}$ is the weighting factor defined based on the number of consecutive sample $r$

$$
w_{r}=r^{m}, m \geq 0, r=1,2, \ldots, N
$$

where $m$ is a power of the weighting factor. The weighting factor with parameter $m>0$ enables the decrease of importance of the samples at the moment of excitation. The interpretation of WRMS maps allows for the determination of the shape and location of the existing defects. In general, the areas with higher WRMS values can indicate the possible locations of damage that are related to the reduction of material stiffness and may be in the form of cracks, corrosion, or delamination [26].

\section{Results and Discussion}

\subsection{Dispersion Curves}

Before analyzing the defects in the lap joints, the characteristics of Lamb waves were determined for two specimens: a single steel plate with a thickness of $3 \mathrm{~mm}$ and dimensions of $240 \mathrm{~mm} \times 300 \mathrm{~mm}$, and two steel plates that were adhesively bonded with an adhesive layer with a thickness of $0.2 \mathrm{~mm}$. In each plate, a five-cycle Hanning windowed sine function with center frequencies of $50 \mathrm{kHz}, 100 \mathrm{kHz}$, and $200 \mathrm{kHz}$ was used as an excitation signal. Out-of-plane vibration signals were measured in 101 points that were evenly distributed along a line with a length of $10 \mathrm{~cm}$. The wavenumber-frequency relations (Figure 6) were obtained using 2D-FFT (cf. $[23,38]$ ). In the experimental results, theoretical dispersion curves that were obtained using GUIGUW software [39] based on the semi-analytical finite-element formulation [40] were superimposed.

In general, in the single plate, both $\mathrm{S}_{0}$ and $\mathrm{A}_{0}$ modes can propagate in the considered frequency range up to $200 \mathrm{kHz}$. However, the applied actuator utilizing the thickness-wise expansion effect enabled mainly exciting the fundamental A0 mode and the influence of the S0 mode was insignificant, as it can be seen in Figure 6a. The group velocities of $A_{0}$ mode were $2981.5 \mathrm{~m} / \mathrm{s}, 2575.7 \mathrm{~m} / \mathrm{s}$, and $2062.7 \mathrm{~m} / \mathrm{s}$ for the excitation frequencies of $200 \mathrm{kHz}, 100 \mathrm{kHz}$, and $50 \mathrm{kHz}$, respectively, giving the wavelengths values of $14.9 \mathrm{~mm}, 25.7 \mathrm{~mm}$, and $41.3 \mathrm{~mm}$. Figure $6 \mathrm{~b}$ shows the dispersion curves for two adhesively bonded plates. In this case, three modes could propagate in the frequency range up to $200 \mathrm{kHz}\left(\mathrm{S}_{0}, \mathrm{~A}_{0}\right.$ and $\left.\mathrm{A}_{1}\right)$, however, in the performed experiment, the $\mathrm{A}_{0}$ mode was dominant. It was noted that the $\mathrm{A}_{0}$ mode dispersion curves were similar for both plates, indicating that this mode will transmit across the waveguide transitions. The group velocities of the $\mathrm{A}_{0}$ mode propagating in two adhesively bonded plates were $2865.6 \mathrm{~m} / \mathrm{s}, 2448.5 \mathrm{~m} / \mathrm{s}$, and $2045.8 \mathrm{~m} / \mathrm{s}$ for the excitation frequencies of $200 \mathrm{kHz}, 100 \mathrm{kHz}$, and $50 \mathrm{kHz}$, respectively, giving the wavelengths values of $14.3 \mathrm{~mm}, 24.5 \mathrm{~mm}$, and $40.9 \mathrm{~mm}$. 

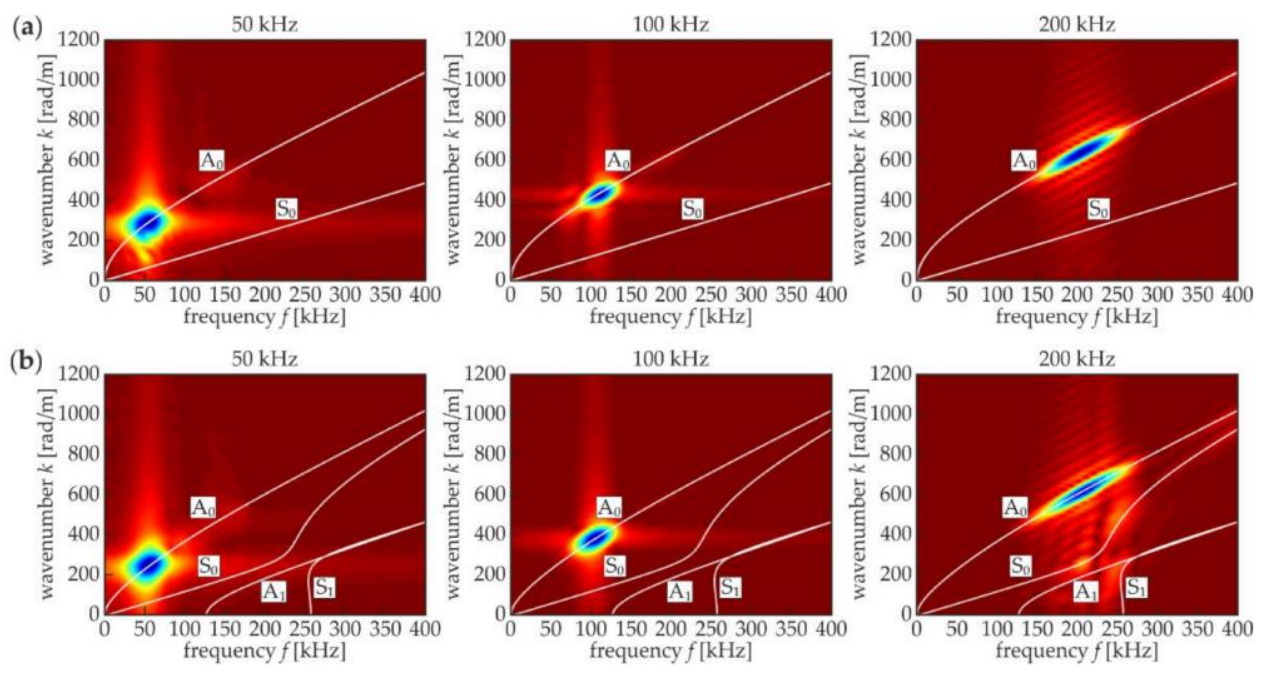

Figure 6. Experimental and theoretical dispersion curves obtained for different excitation frequencies of $50 \mathrm{kHz}, 100 \mathrm{kHz}$, and $200 \mathrm{kHz}$ : (a) steel $3 \mathrm{~mm}$ plate $\left(E=195.2 \mathrm{GPa}, v=0.3, \rho=7741.7 \mathrm{~kg} / \mathrm{m}^{3}\right)$; and (b) two adhesively jointed steel $3 \mathrm{~mm}$ plates ( $\left.E=195.2 \mathrm{GPa}, v=0.3, \rho=7741.7 \mathrm{~kg} / \mathrm{m}^{3}\right)$ adhesively bonded with the adhesive layer of a thickness of $0.2 \mathrm{~mm}\left(E=5 \mathrm{GPa}, v=0.35, \rho=1130 \mathrm{~kg} / \mathrm{m}^{3}\right)$.

\subsection{SLDV Maps}

Figure 7 shows snapshots of the guided wave propagation signals that were obtained in the experimental scanning of the analyzed specimens. The SLDV maps are presented at the time instance of $27.7 \mu \mathrm{s}$. Disturbances of the wavefront shape on the disbond area were visible for each specimen from \#2-\#9 when compared with the intact specimen \#1. The differences were more or less considerable, depending on the geometry of the defect. The most significant disturbances were observed for the specimens with stripped defects skewed and parallel to the primary direction of propagation (\#4-\#6). For specimens that had the disbond area in the shape of a strip perpendicular to the direction of propagation (\#2,\#7), the changes were not clearly visible. The exception was specimen \#3, which had no adhesive near the edge of the overlap and resulted in the limited appearance of the wavefront on the overlap surface. Internal defects (\#8, \#9) were moderately detectable. In summary, the presence of the defects in the damaged specimens was visible in the maps, but their geometry was not determinable.
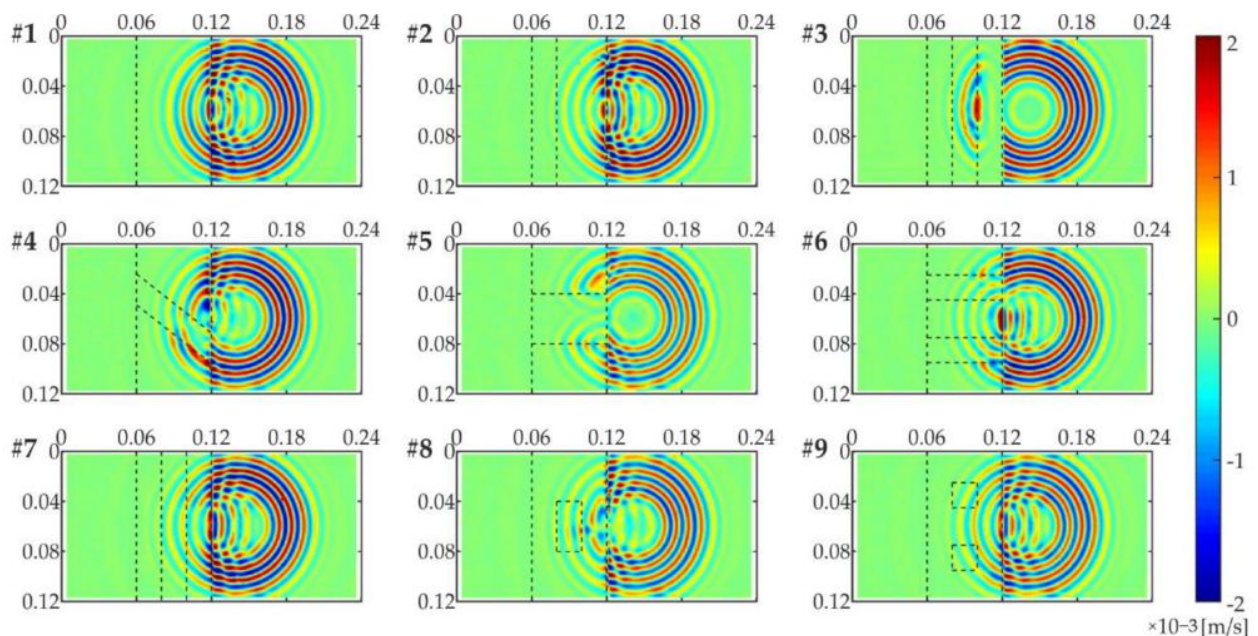

Figure 7. Scanning laser Doppler vibrometry (SLDV) maps of considered joints at the time instance $27.7 \mu$ s (dimensions of the joint are given in meters; the adhesive was $0.06-0.12 \mathrm{~m}$ ). 


\subsection{WRMS Imaging}

\subsubsection{Influence of Time Window and Weighting Factor}

Figure 8 shows the WRMS that was calculated for specimen \#5 using Equation (2). Different values of the weighting factor and time window were applied. In all calculations, the beginning of the time window $t_{1}$ was always set as zero, so the length of the time window was $T=t_{2}$. The obtained damage maps are presented as logarithmic values of WRMS. The analysis of the results led to the conclusion that the time window is a significant factor for the readability of visualizations. According to the visual assessment, the clearness of the WRMS maps increased with the increase in the time window. For this reason, the longest time window $(T=3.0 \mathrm{~ms})$ was tentatively chosen for the damage imaging of the other specimens (as presented further). It is also worth noting that the weighting factor was not negligible. The constant weighting factor $\left(w_{r}=1\right)$ was not efficient when compared with others that increased with time. The maps were not clear enough and the influence of the incident wave at the excitation point was highly visible. These effects were not observable for the weighting factors $w_{r}=r$ and $w_{r}=r^{2}$, as represented by the linear or square function of time, respectively. Their effectiveness was comparable and significantly higher than the constant weighting factor.

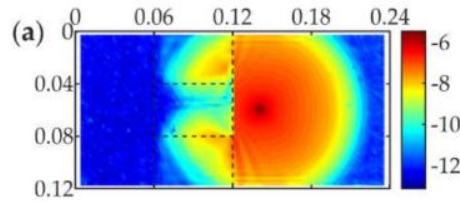

(b)
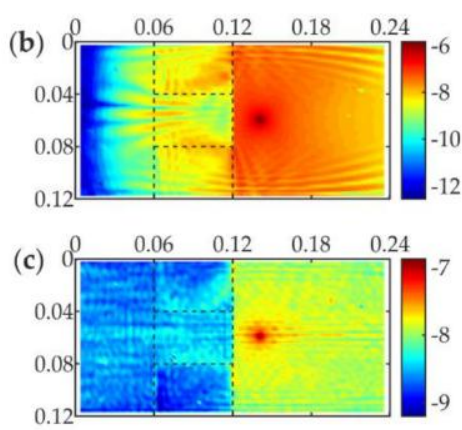

(d)
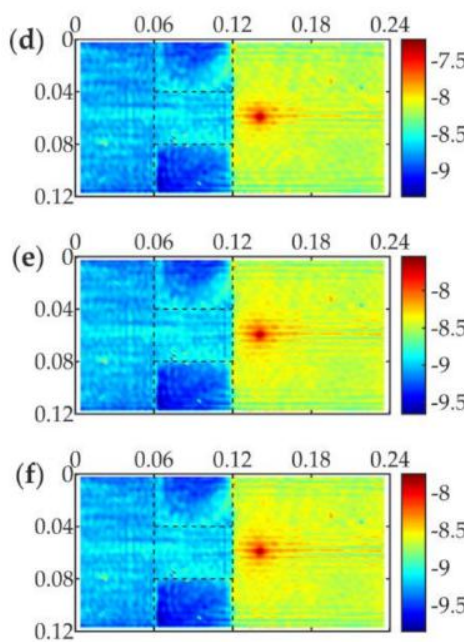
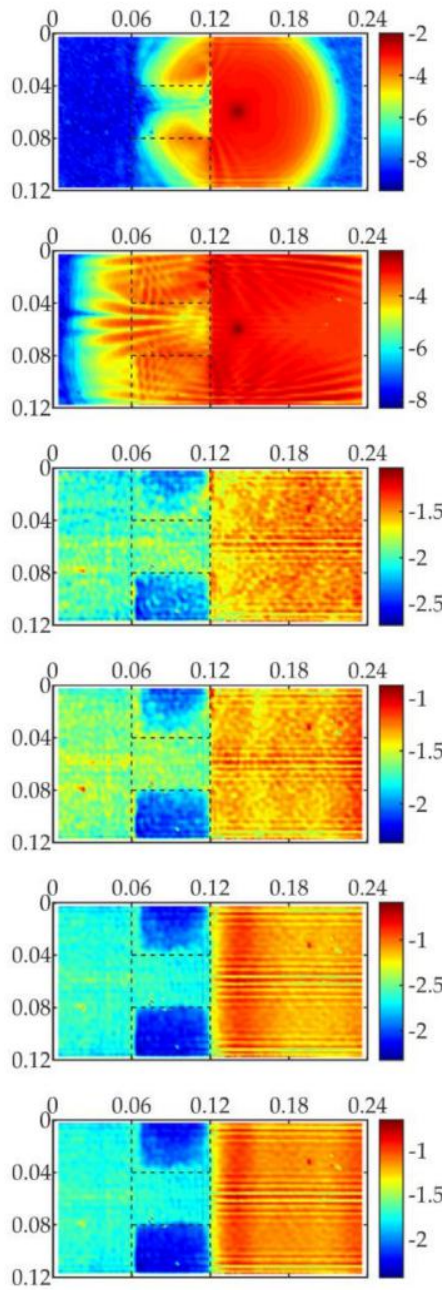
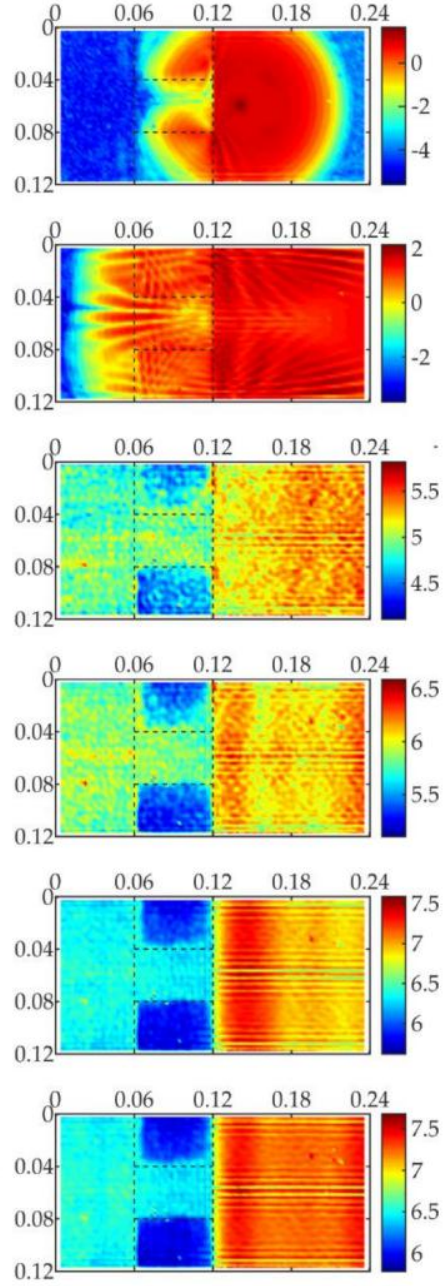

Figure 8. Weighted root mean square (WRMS) maps (values in $(\mathrm{m} / \mathrm{s})$ ) for specimen \#5 for different weighting factors $w_{r}=1$ (first column), $w_{r}=r$ (second column), $w_{r}=r^{2}$ (third column) and varying time window: (a) $T=0.03 \mathrm{~ms}$; (b) $T=0.05 \mathrm{~ms}$; (c) $T=0.50 \mathrm{~ms}$; (d) $T=1.00 \mathrm{~ms}$; (e) $T=2.00 \mathrm{~ms}$; and, (f) $T=3.00 \mathrm{~ms}$. 
To assess the clearest variant of the WRMS, damage maps for adhesive joints with internal defects $(\# 8, \# 9)$ were prepared (Figure 9). The identification of the defect geometry for these specimens was possible, however, some differences between the WRMS maps can be observed. A comparison of the different weighting factors for both of the specimens showed the advantage of a variant with the linear function.
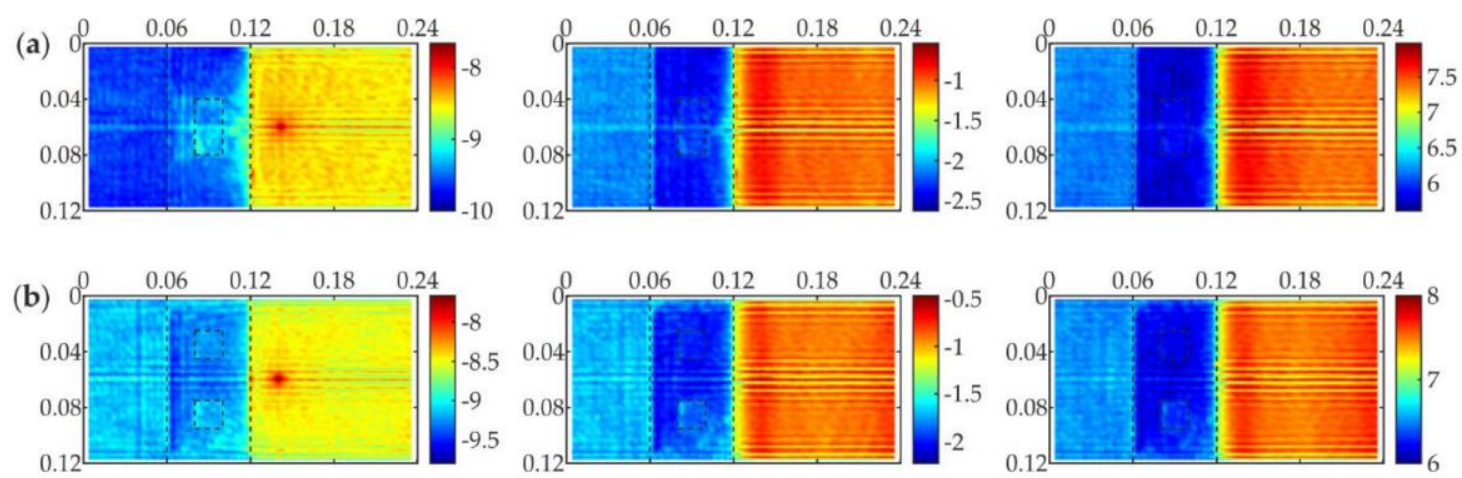

Figure 9. WRMS maps (values in $(\mathrm{m} / \mathrm{s})$ ) for joints with internal defects for constant time window $(T=3.00 \mathrm{~ms})$ and different weighting factors $w_{r}=1$ (first column), $w_{r}=r$ (second column), $w_{r}=r^{2}$ (third column): (a) specimen \#8; and, (b) specimen \#9.

\subsubsection{Influence of Defect Shape and Position}

Figure 10 shows the WRMS maps for all of the considered specimens \#1-\#9. The parameters of the WRMS calculations were assumed as follows: the time window $T=3.00 \mathrm{~ms}$ and the weighting factor $\left(w_{r}=r\right)$. The intensification of the WRMS maps could be observed at the disbond areas, where the values were greater than for the properly bonded parts. This means that the amplitudes of propagating waves vary more significantly if there is no direct connection between the bonded parts. It is worth noting that the clearness of the maps increased with the difference between values that were obtained for the disbonded and properly bonded areas.
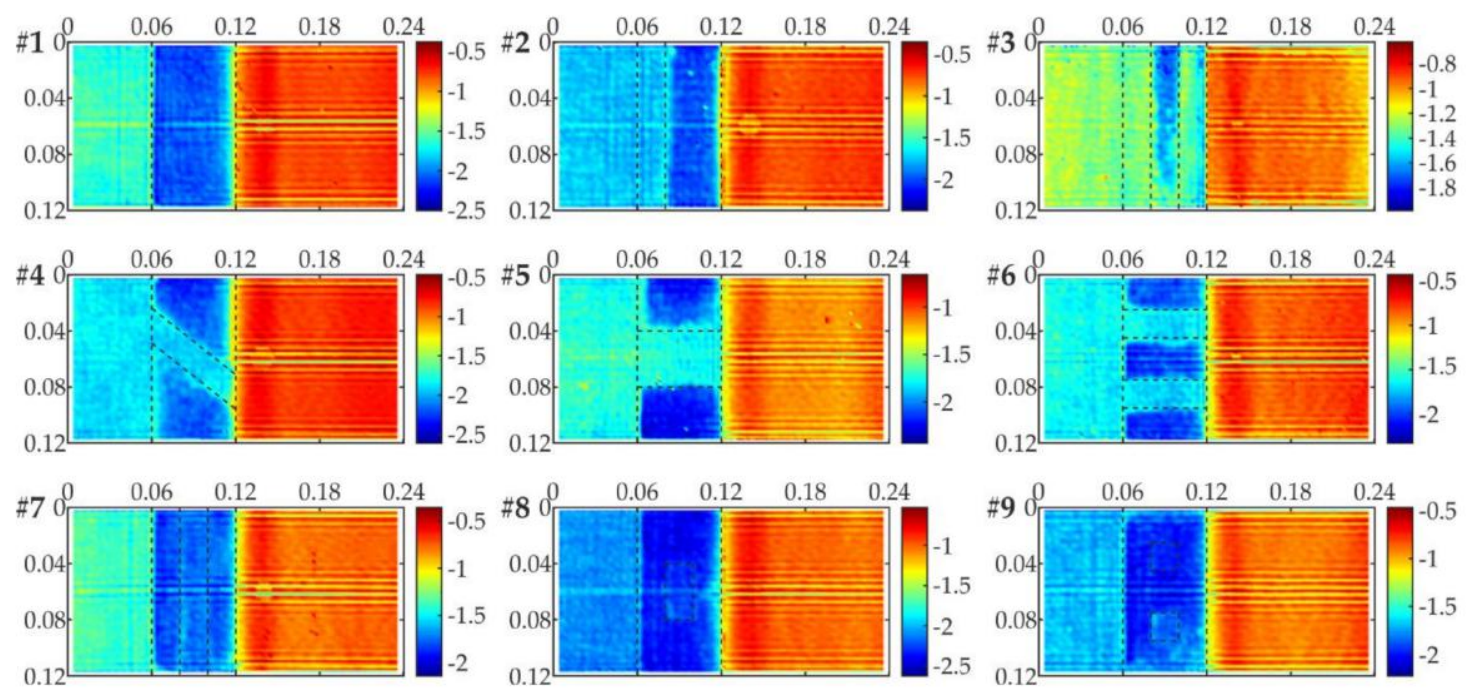

Figure 10. WRMS maps (values in $(\mathrm{m} / \mathrm{s}))$ for specimens \#1-\#9 $\left(T=3.00 \mathrm{~ms}, w_{r}=r\right)$. 
The presence of defects was possible to determine in all cases, moreover, their shapes were also identifiable. The clearest damage image was obtained for specimens \#4-\#6, as well as specimens \#2 and \#3. Internal damages in specimens \#7-\#9 were also possible to identify; however, the damage maps had poorer quality. It is worth noting that the geometry of the identified defects was not in ideal agreement with the assumed one. In some cases, minor irregularities were visible, especially for samples that were intended as symmetric. This was an effect of inaccuracies in the process of the specimen preparation. The verification of the actual state of the adhesive layer was obtained after separating the joints (cf. Figure 3). It is clear that the adhesive leakages to the areas that are covered with PTFE tape were not identified in the maps, which means that the tape prevented the plates from being connected. On the other hand, the kissing defects were clearly noticeable (cf. Figure 3).

Figure 11 also shows the WRMS maps for all of the considered specimens (\#1-\#9), but for the square weighting factor $\left(w_{r}=r^{2}\right)$. The visual assessment of the presented maps led to conclusions that were similar to the ones resulting from analysis of maps for the linear weighting factor $\left(w_{r}=r\right)$. The value of $m$ power affected the clearness of images: the ones for the linear weighting factor appeared to be clearer. Based only on the visual assessment of the defect images, it was not possible to judge which variant of weighting factor provided the clearest results.
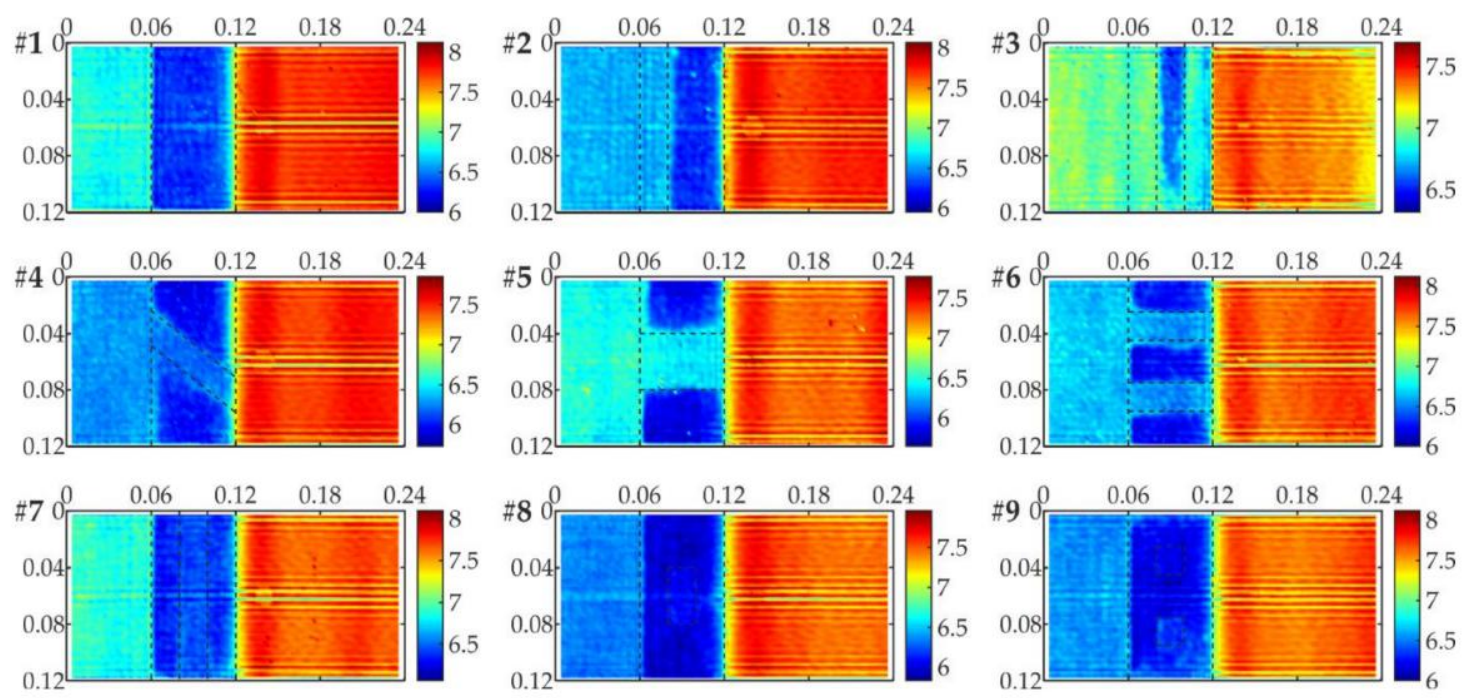

Figure 11. WRMS maps (values in $(\mathrm{m} / \mathrm{s}))$ for specimens \#1-\#9 $\left(T=3.00 \mathrm{~ms}, w_{r}=r^{2}\right)$.

\subsubsection{Influence of Excitation Frequency}

An additional aspect of the analysis was the influence of the excitation frequency on the obtained results. Figures 12 and 13 show the WRMS maps for specimens \#6 and \#7 for the linear and square weighting factors, respectively. The measurement of the joints was repeated three times, with different excitation frequencies, namely $200 \mathrm{kHz}, 100 \mathrm{kHz}$, and $50 \mathrm{kHz}$. It was observed that the excitation frequency was an important factor that significantly affected the readability of the maps. The efficiency of the WRMS damage imaging increased with the increase in the excitation frequency value. 

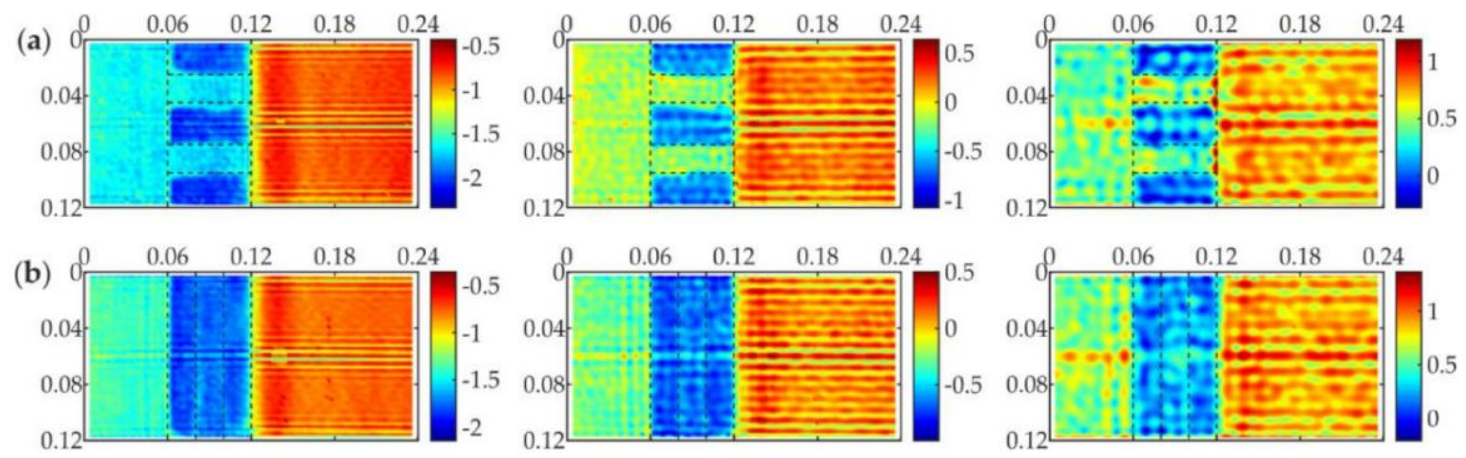

Figure 12. WRMS maps (values in $(\mathrm{m} / \mathrm{s})$ ) with linear weighting factor $\left(w_{r}=r\right)$, time window $T=3.00 \mathrm{~ms}$ and with different excitation frequencies $f=200 \mathrm{kHz}$ (first column), $f=100 \mathrm{kHz}$ (second column), $f=50 \mathrm{kHz}$ (third column): (a) specimen \#6; and (b) specimen \#7.
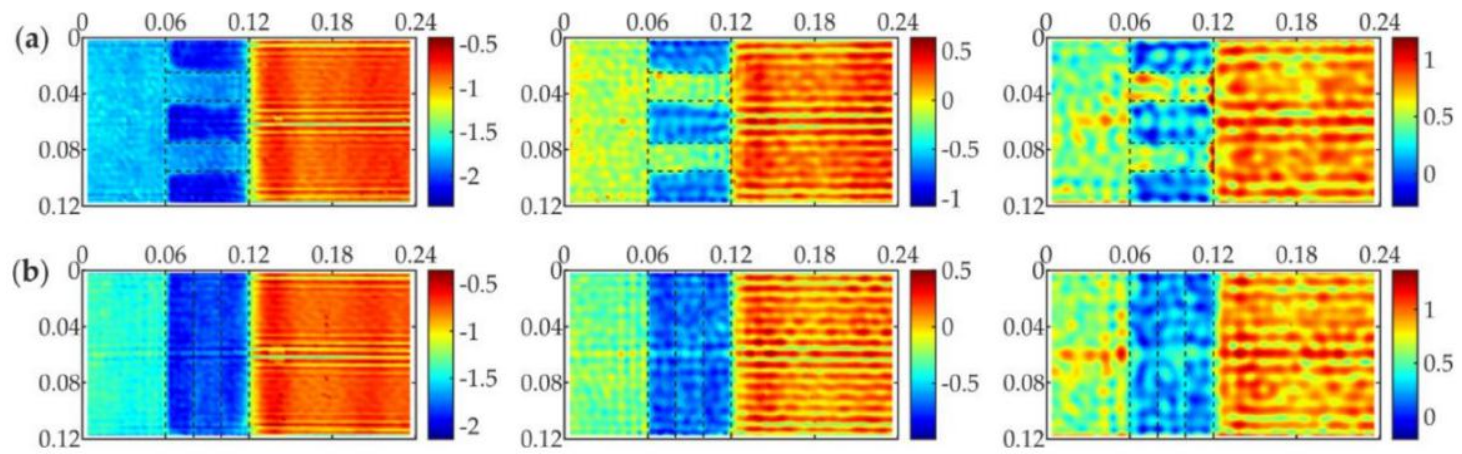

Figure 13. WRMS maps (values in $(\mathrm{m} / \mathrm{s})$ ) with square weighting factor $\left(w_{r}=r^{2}\right)$, time window $T=3.00 \mathrm{~ms}$ and with different excitation frequencies $f=200 \mathrm{kHz}$ (first column), $f=100 \mathrm{kHz}$ (second column), $f=50 \mathrm{kHz}$ (third column): (a) specimen \#6; and, (b) specimen \#7.

\subsubsection{WRMS Histograms}

The WRMS method enables one to differentiate the areas of a properly prepared adhesive film and its defects. In addition to the visual assessment of prepared maps, a numerical analysis of its calculated values can be performed with the use of statistical analysis. The purpose is to prepare a histogram of calculated WRMS values that is expected to reveal the bimodal distribution of the sample population (concentrated on two values responding to disbonded and properly bonded areas). This presents the possibility for the quantitative determination of the optimal values of WRMS parameters. As observed from the images in Figures 10 and 11, higher WRMS values were obtained in the disbonded areas, whereas the lower ones occurred in the areas of good adhesion. To provide a clear interpretation of the WRMS histograms, the analysis was limited to the surface of the overlap (area of the adhesive joint).

In the first step, the influence of the time window on WRMS histograms was considered. Figures 14 and 15 present the WRMS histograms for specimen \#5 with different values of time window and different weighting factors $w_{r}=r$ and $w_{r}=r^{2}$, respectively. Additionally, to emphasize the characterization of the obtained distributions, each histogram was approximated by the probability density function with the use of the kernel smoother in a MATLAB ${ }^{\circledR}$ environment (shown as a red line). It was clear that, for higher time window values ( $0.50 \mathrm{~ms}$ and more), a population of WRMS values formed a bimodal distribution that was represented by a function with two conspicuous peaks values. As concluded before, the clearness of the defect image was related to the difference between the values that were obtained for health and poor adhesion areas of the overlap. For the histograms, this difference was interpreted as the distance between the peak values that were measured along the horizontal axis. For each diagram (if possible), peak values were localized. To compare the results that were obtained 
for different time window values, the differences between the scales were eliminated by dividing the measured distances by the analyzed range of fitted distributions. Calculated values for both variants of weighting factors are presented in Table 2 (only if the bimodal distribution was obtained). It could be seen that the increase in time window caused the peaks to occur at longer distances. The clarity of the maps increased with the growth of the distance between peaks, which meant that the longer time window positively influenced the clearness of the maps. This fact justifies the selection of the largest value of time window $(T=3.00 \mathrm{~ms})$ for the prepared WRMS maps.
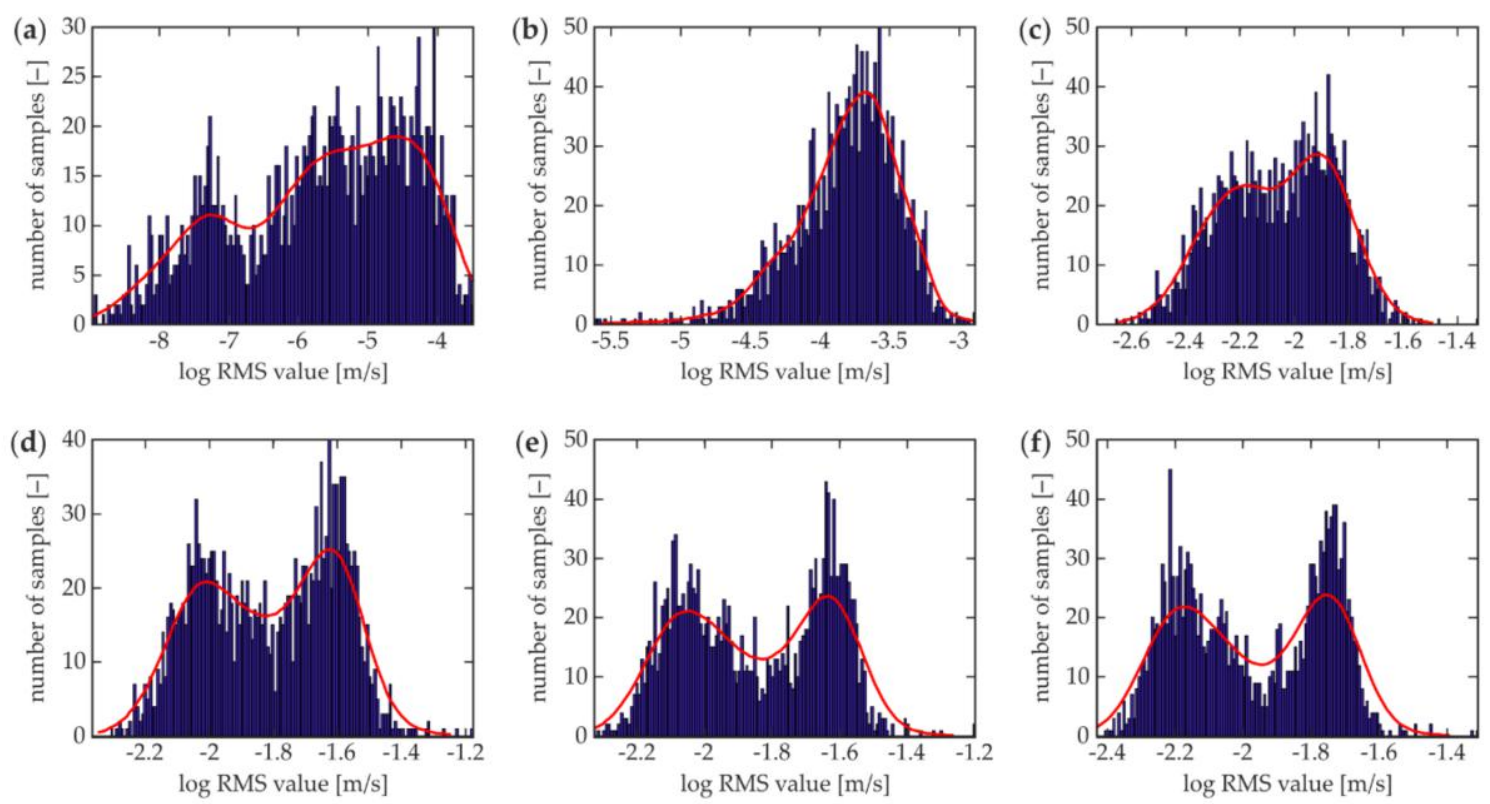

Figure 14. Histograms of WRMS values $\left(w_{r}=r\right)$ for specimen \#5 with different time windows: (a) $T=0.03 \mathrm{~ms}$; (b) $T=0.05 \mathrm{~ms}$; (c) $T=0.50 \mathrm{~ms}$; (d) $T=1.00 \mathrm{~ms}$; (e) $T=2.00 \mathrm{~ms}$; and, (f) $T=3.00 \mathrm{~ms}$.
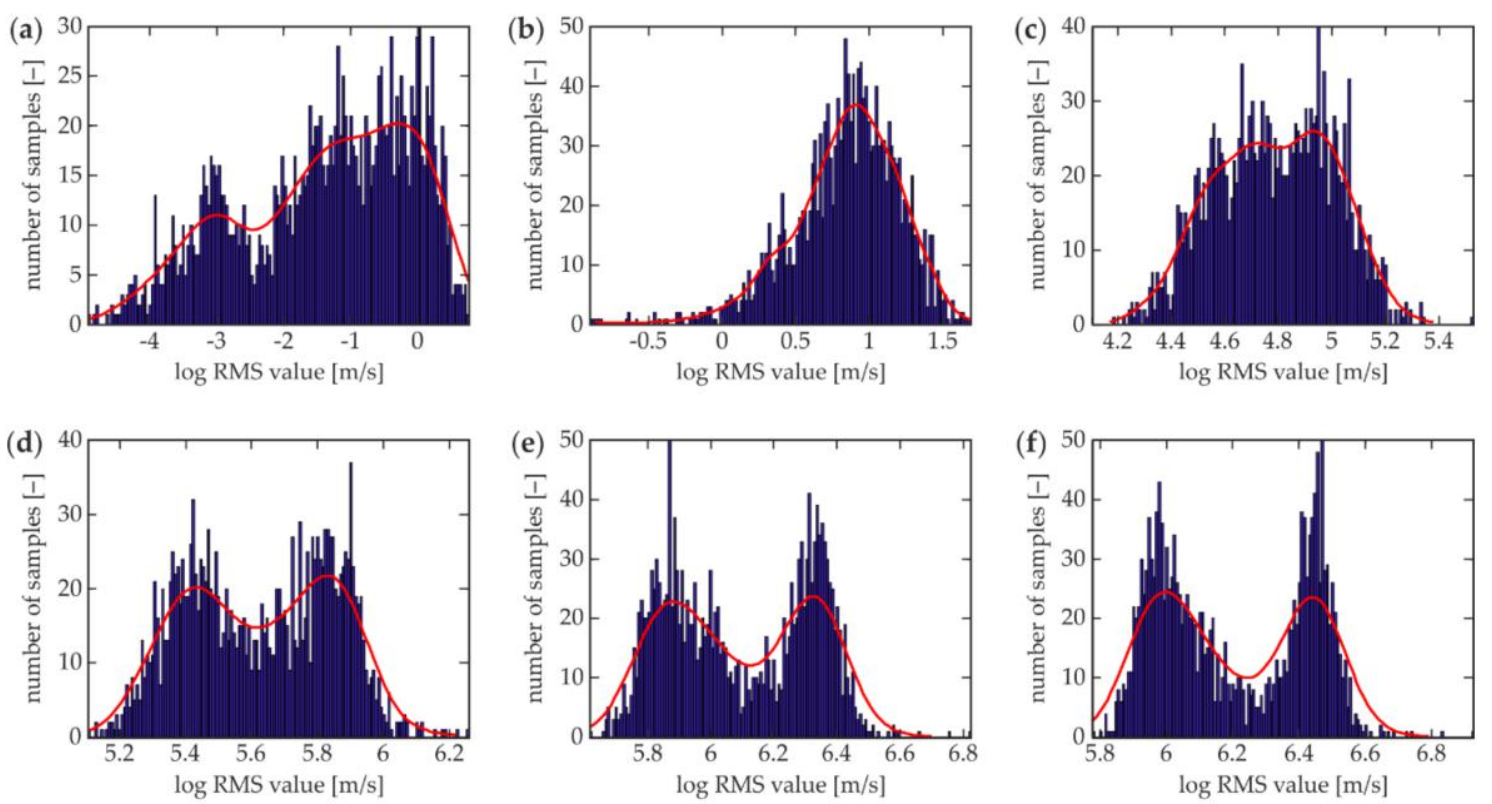

Figure 15. Histograms of WRMS values $\left(w_{r}=r^{2}\right)$ for specimen \#5 with different time windows: (a) $T=0.03 \mathrm{~ms}$; (b) $T=0.05 \mathrm{~ms}$; (c) $T=0.50 \mathrm{~ms}$; (d) $T=1.00 \mathrm{~ms}$; (e) $T=2.00 \mathrm{~ms}$; and (f) $T=3.00 \mathrm{~ms}$. 
Table 2. Calculated values of relative peaks distance of bimodal distribution for specimen \#5.

\begin{tabular}{ccc}
\hline Time Window $(\mathrm{ms})$ & Relative Peaks Distance $\left(w_{r}=r\right)(\%)$ & Relative Peaks Distance $\left(w_{r}=r^{\mathbf{2}}\right)(\%)$ \\
\hline 0.03 & - & - \\
0.05 & - & - \\
0.50 & 18.67 & 12.67 \\
1.00 & 30.67 & 33.33 \\
2.00 & 34.67 & 34.67 \\
3.00 & 35.33 & 37.33 \\
\hline
\end{tabular}

To move forward, histograms for all of the specimens were prepared with the time window $T=3.00 \mathrm{~ms}$. Figure 16 presents the histograms with the linear weighting factor. For the intact joint (specimen \#1), a common unimodal distribution was obtained. The calculated values were concentrated about a singular mode that represented the undamaged area of the adhesive joint. Typical bimodal distributions were obtained for specimens with a clear defect image (\#2-\#6). For specimens \#7\#9, the distributions were likely to be unimodal, but when compared with specimen \#1, their shapes were not that regular, and it was clear that their widths were greater than that of specimen \#1. This may result in the conclusion that the defect was present, but it could not be clearly observable. Figure 17 shows the histograms with the square weighting factor. The conclusions from the analysis of each histogram were similar to ones based on Figure 16.
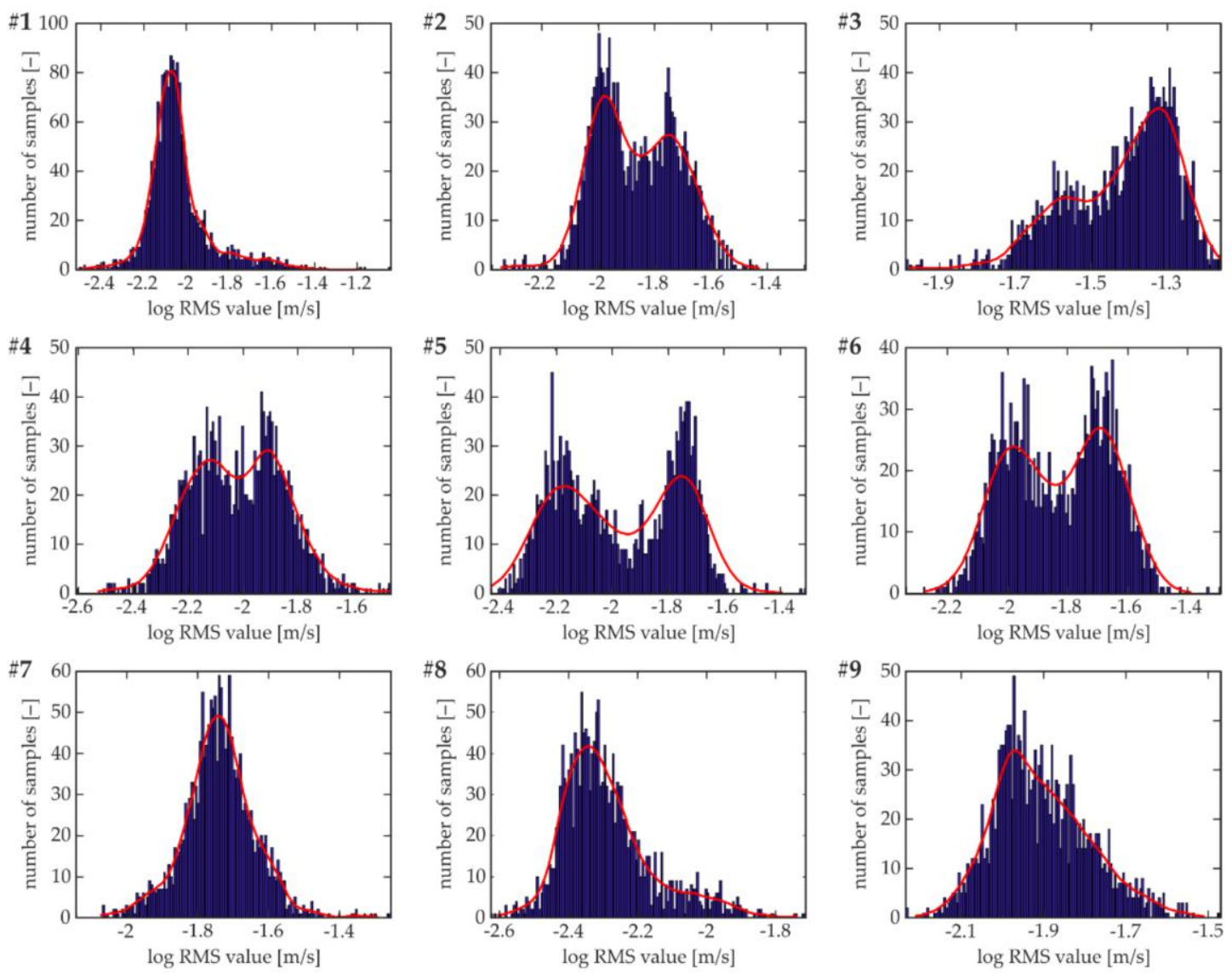

Figure 16. Histogram of WRMS values for specimens \#1-\#9 $\left(T=3.00 \mathrm{~ms}, w_{r}=r\right)$. 

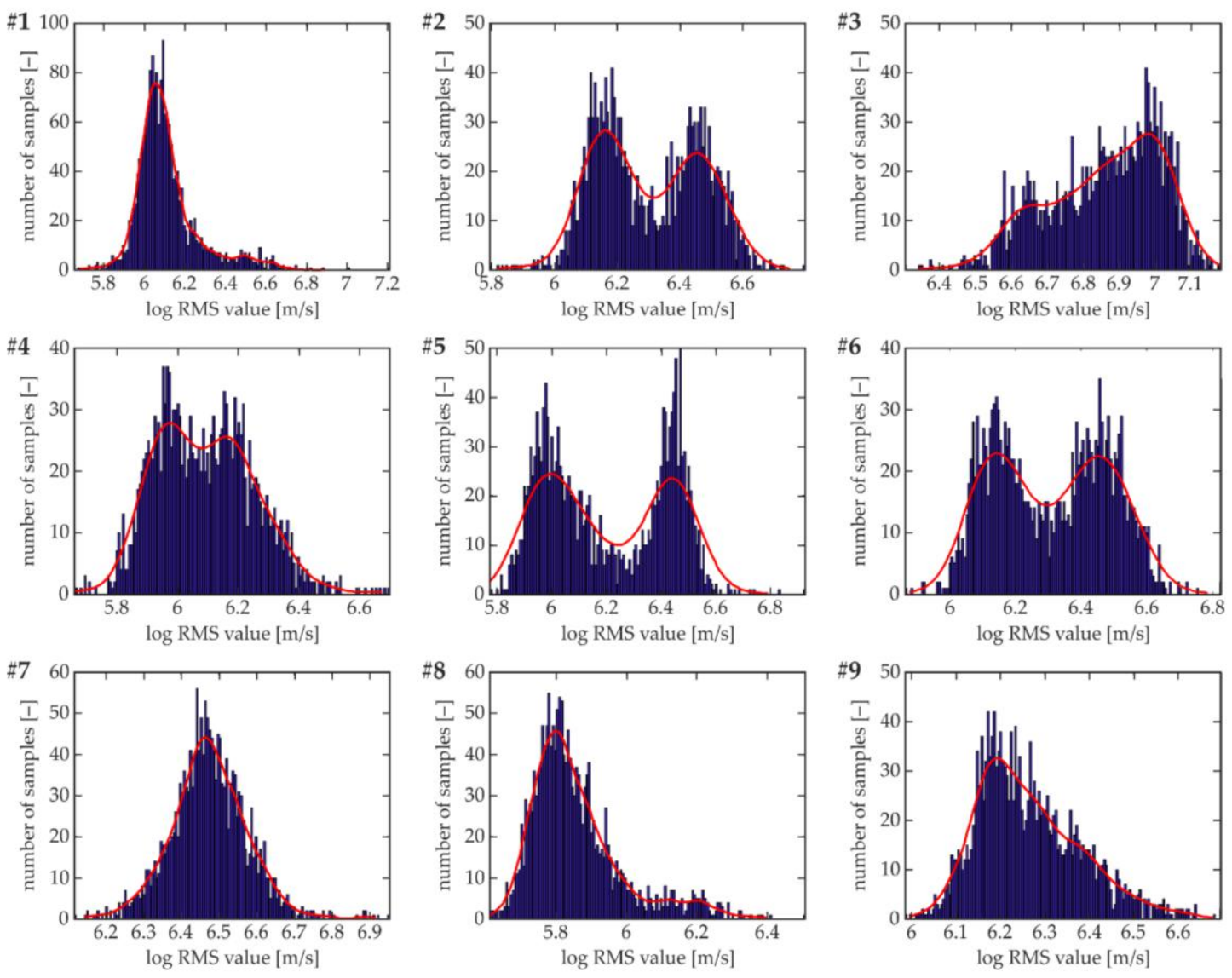

Figure 17. Histogram of WRMS values for specimens \#1-\#9 $\left(T=3.00 \mathrm{~ms}, w_{r}=r^{2}\right)$.

Figure 18 shows the relationships between the relative peak distance and the weighting factor that is represented by the power $m$ for specimens \#2-\#6 that clearly presented bimodal distributions. It could be seen that for most of the specimens, higher values of power $m$ resulted in the greater value of relative peaks distance. This means that the higher the value of $m$, the clearer the image of the defect on the WRMS maps. It is worth noting that the value of the relative peaks distance stabilized at a specific value of $m$ individually for each defect, so the increase in $m$ could not infinitely the improve the quality of maps. Furthermore, specimen \#4 provided a different relationship than the others where the relative distance between the peaks at the beginning increased with power $m$ and then decreased. Maximal values were observed for the power $m$ between 1 and 1.5. Based on the calculations presented above, it was concluded that the proposed analysis provides the opportunity to improve the process of determining the optimal value of the weighting factor (in fact, the power $m$ ) for damage imaging using WRMS.

An attempt to quantitatively analyze the defects was performed based on the statistical analysis of the calculated WRMS values. Histograms and their approximations by probability density functions were prepared for different values of power $m$ for specimens with a bimodal distribution (\#2-\#6). The limit point (here, the central point) in the peaks distance was determined as the mean value between peak values (along the horizontal axis). As previously mentioned, poor adhesion areas are related to higher values of WRMS. For that reason, the number of values that are above the central point value were counted, representing the number of points where the defect occurred. The percentage of points with higher values can be interpreted as the relative surface of the defect. Based on the relationships that are presented in Figure 19, it was clear that for most of the specimens, the relative defect surface did not vary significantly in relation to power $m$ and it moderately decreased with its value. The exception was the defect in specimen \#4 that presented the opposite relationship. 
When comparing the results with measurements that were conducted on the real separated specimen (Table 1), it was clear that the good agreement of the proposed approach was obtained only for defect \#3 (calculated mean value of relative surface is $68.5 \%$ and measured is $68.21 \%$ ). For other specimens, the differences were much higher (calculated values ranged from $45 \%$ to $55 \%$ and measured between $33 \%$ and $37 \%$ ). The reason for these discrepancies may possibly be related to the method of determining the limit point for counting the number of points that are related to the defect surface. Due to the complexity of bimodal distributions (e.g., different parameters of both modes), further analyses should be conducted.

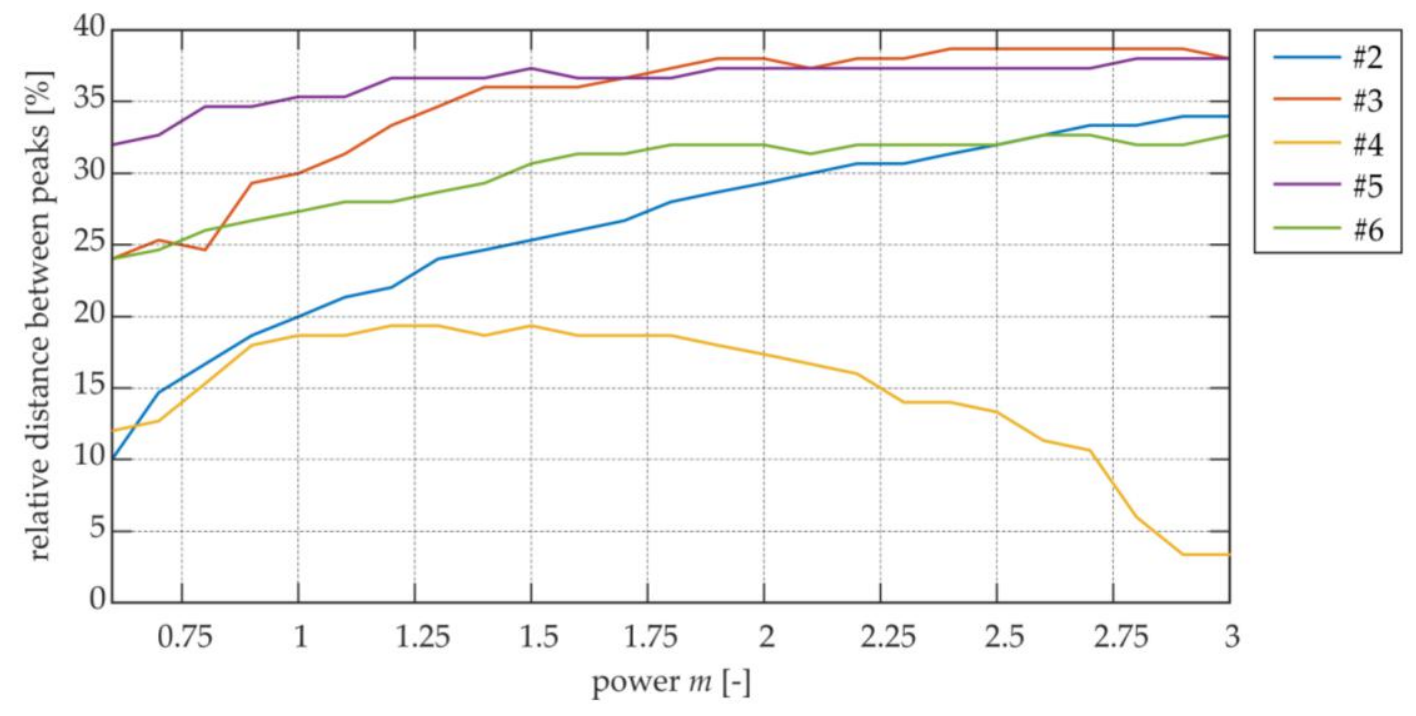

Figure 18. Relationships between the relative peak distance of WRMS histograms and weighting factor (represented by power $m$ ) for specimens \#2-\#6.

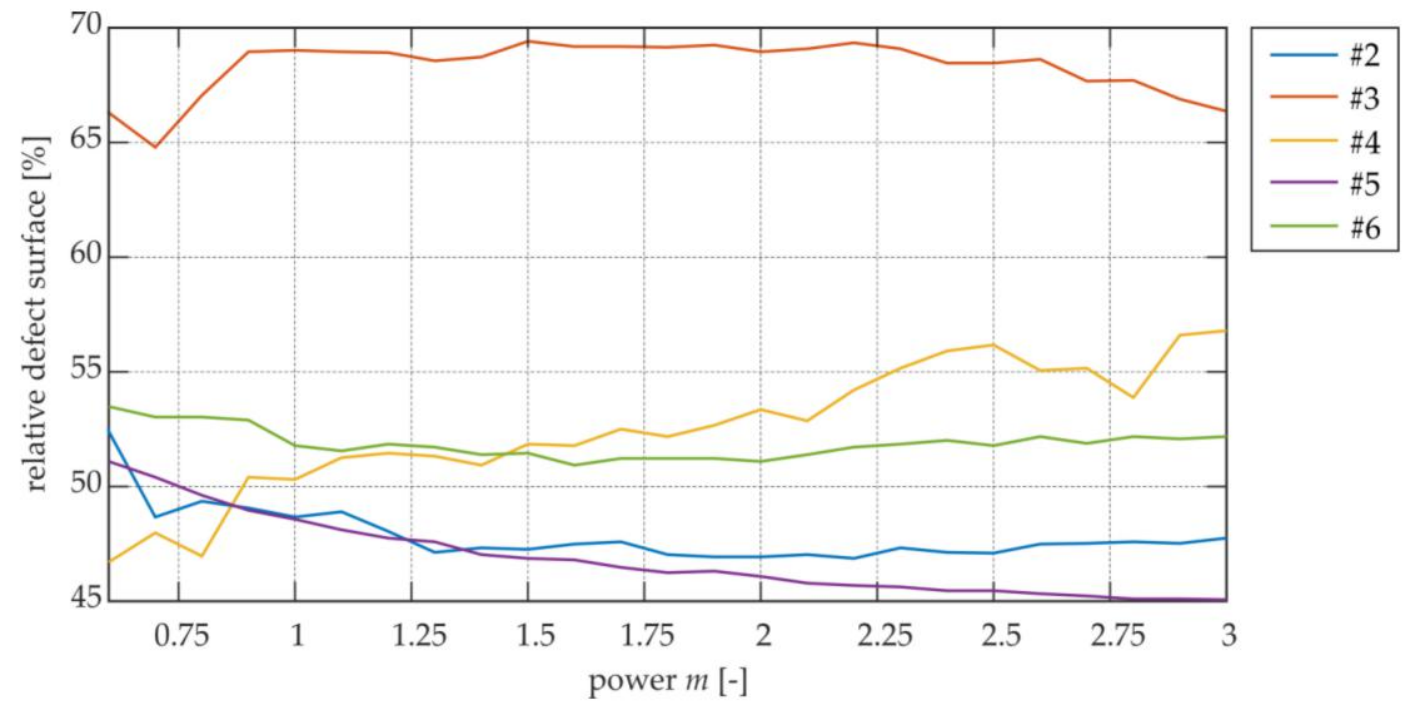

Figure 19. Relationships between the relative defect surface and weighting factor (represented by power $m$ ) for specimens \#2-\#6.

One additional aspect of this research included the statistical analysis of the influence of the excitation frequency. Figure 20 shows the WRMS histograms for specimen \#6 with different excitation frequencies. For the lowest value $(50 \mathrm{kHz})$, the unimodal (but asymmetric) distribution was obtained. Higher frequencies $(100 \mathrm{kHz}$ and $200 \mathrm{kHz})$ showed typical bimodal distributions with different 
characterization. To compare them, the relative peak distance was calculated. For $100 \mathrm{kHz}$, a value of $34.67 \%$ was obtained, whereas for $200 \mathrm{kHz}$, it was $27.33 \%$. This meant that the $100 \mathrm{kHz}$ frequency provided results with more differentiated WRMS values obtained in areas with good and poor quality (resulting in clearer defect image). Furthermore, the percentage of the defect surface was determined with the use of the above-presented method with the central limit point. For $100 \mathrm{kHz}$, the result was $35.67 \%$ and for $200 \mathrm{kHz}$, a value of $51.78 \%$ was achieved. When compared to the measured value (33.33\%, Table 1), the nearest value was obtained for $100 \mathrm{kHz}$. However, due to the lack of results for other specimens revealing bimodal distribution, it was not possible to conclude on the supremacy of this frequency. Further research could help to solve this problem.
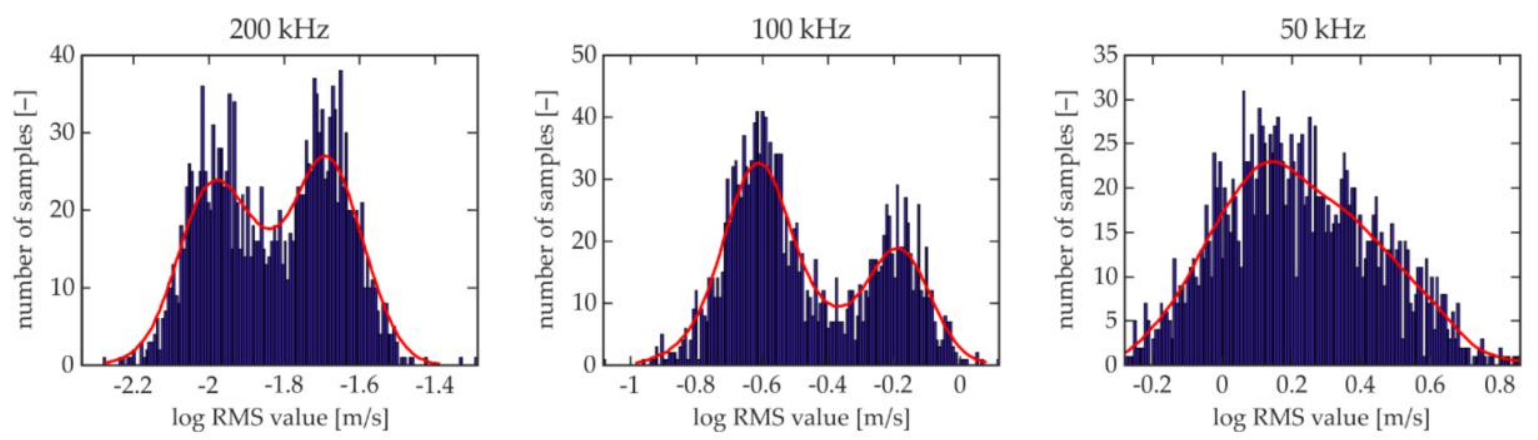

Figure 20. Histograms of WRMS values for specimen \#6 with different excitation frequencies ( $T=3.00 \mathrm{ms,}$ $\left.w_{r}=r\right)$.

\section{Conclusions}

In this paper, an experimental analysis of the Lamb wave interaction with damage in the adhesively bonded joints was conducted. The study consisted of a visual assessment and statistical analysis of the obtained results. The presented investigations support the following conclusions:

- The analysis of maps that were obtained from the SLDV measurements provided the initial identification of defects with different efficiencies. The clearness of the SLDV maps varied depending on the shape and position of damage.

- The actual defect shape and location were determinable based on the appropriate damage imaging, where recorded out-of-plane vibrations were processed by means of the WMRS. The effectiveness of the applied method was strongly dependent on the calculation parameters (weighting factor and time window), excitation frequency, and a type of damage.

- The extension of the time window led to the increase in differences in the WRMS values between the damaged and undamaged areas of the adhesive joint. As a result, defects in the adhesive film could be identified more accurately.

- By comparing different variants of weighting factors, the constant one did not provide efficient results due to the high influence of the incident wave at the excitation point. This effect was reduced by the weighting factor, which was represented by the linear or square function that achieved comparable results. For specimens with internal defects, moderately greater effectiveness of the linear variant was observed.

- The shape and location of defects had a great impact on the effectiveness of their identification. Both the presence and the size of defects were possible to determine in all of the contested specimens based on the WRMS damage maps. The clearest results were obtained for stripe defects parallel or skewed to the primary direction of wave propagation. The disbonded areas in the shape of the strip perpendicular to the direction of wave propagation were also determinable, however, the identification was easier when such area was at the beginning or at the end of the lap. The most difficult to detect were the defects in the internal part of the adhesive film. 
The differentiation of effectiveness of the method for different types of defects resulted from the occurrence of different wave phenomena at the boundaries of defects. Stripe defects, skewed, or parallel to the direction of propagation triggered a diffraction of wave fronts that provided a significant disturbance in wave propagation and resulted in a higher intensification of signals. Defects in the shape of a perpendicular strip were related to wave reflection that did not disrupt the propagation as diffraction did. Finally, internal defects were the most difficult to identify because of the local characterization of occurring wave phenomena.

- The statistical analysis of the calculated WRMS values successfully supplemented the visual assessment of the damage images. The interpretation of the histograms helped to explain the effects that were observed on the WRMS maps. The use of the relative distance between peaks of bimodal distribution was proposed as the indicator for the optimal determination of WRMS parameters. Based on this indicator, it was proven that the largest value of the time window obtained damage maps with the highest clearness. Moreover, it was possible to determine the range of the optimal value of the weighting factor and to quantify the defect areas. The statistical analysis of the influence of the excitation frequency also enabled a comparison of the effectiveness of the three different frequencies. Two higher frequencies providing bimodal distribution were proven to be more effective than the lowest excitation frequency providing unimodal distribution.

The main conclusion was that the scanning laser Doppler vibrometry and the weighted root mean square processing of guided wave signals could be successfully applied for damage imaging in adhesive films. Additionally, the statistical analysis can be useful in the interpretation of the obtained results. However, the conducted research is an initial step for further analyses that are related to condition assessment in adhesive joints of elements in real engineering structures. The proposed method to determine the optimal value of the weighting factor and to quantify the real defect areas could be further developed. The influence of different excitation frequencies could be also considered more precisely.

Acknowledgments: The research work was carried out within project No. 2015/19/B/ST8/00779, financed by the National Science Centre, Poland. This support is greatly acknowledged by the authors of the study.

Author Contributions: M.R. conceived, designed, and performed the experiments; J.L. contributed analysis tools for damage imaging; M.R., E.W. and J.L. analyzed the data; E.W. and M.R. wrote the paper.

Conflicts of Interest: The authors declare no conflict of interest.

\section{References}

1. Adams, R.D.; Wake, W.C. Structural Adhesive Joints in Engineering; Elsevier Applied Science Publishers: London, UK, 1986; ISBN 978-94-010-8977-7.

2. Karachalios, E.F.; Adams, R.D.; Da Silva, L.F.M. Strength of single lap joints with artificial defects. Int. J. Adhes. Adhes. 2013, 45, 69-76. [CrossRef]

3. Heidarpour, F; Farahani, M.; Ghabezi, P. Experimental investigation of the effects of adhesive defects on the single lap joint strength. Int. J. Adhes. Adhes. 2018, 80, 128-132. [CrossRef]

4. Jeenjitkaew, C.; Guild, F.J. The analysis of kissing bonds in adhesive joints. Int. J. Adhes. Adhes. 2017, 75, 101-107. [CrossRef]

5. Adams, R.D.; Drinkwater, B.W. Nondestructive testing of adhesively-bonded joints. NDT E Int. 1997, 30, 93-98. [CrossRef]

6. Korzeniowski, M.; Piwowarczyk, T.; Maev, R.G. Application of ultrasonic method for quality evaluation of adhesive layers. Arch. Civ. Mech. Eng. 2014, 14, 661-670. [CrossRef]

7. Vijayakumar, R.L.; Bhat, M.R.; Murthy, C.R.L. Non destructive evaluation of adhesively bonded carbon fiber reinforced composite lap joints with varied bond quality. AIP Conf. Proc. 2012, 1430, 1276-1283. [CrossRef]

8. Tighe, R.C.; Dulieu-Barton, J.M.; Quinn, S. Identification of kissing defects in adhesive bonds using infrared thermography. Int. J. Adhes. Adhes. 2016, 64, 168-178. [CrossRef]

9. Vijaya Kumar, R.L.; Bhat, M.R.; Murthy, C.R.L. Evaluation of kissing bond in composite adhesive lap joints using digital image correlation: Preliminary studies. Int. J. Adhes. Adhes. 2013, 42, 60-68. [CrossRef] 
10. Vijaya kumar, R.L.; Bhat, M.R.; Murthy, C.R.L. Analysis of composite single lap joints using numerical and experimental approach. J. Adhes. Sci. Technol. 2014, 28, 893-914. [CrossRef]

11. Roth, W.; Giurgiutiu, V. Structural health monitoring of an adhesive disbond through electromechanical impedance spectroscopy. Int. J. Adhes. Adhes. 2017, 73, 109-117. [CrossRef]

12. Giurgiutiu, V. Structural Health Monitoring with Piezoelectric Wafer Active Sensors; Elsevier: Amsterdam, The Netherlands, 2008.

13. Ostachowicz, W.; Kudela, P.; Krawczuk, M.; Zak, A. Guided Waves in Structures for SHM; Wiley: Hoboken, NJ, USA, 2012; ISBN 9781119965855.

14. Rose, J.L. Ultrasonic Guided Waves in Solid Media; Cambridge University Press: New York, NY, USA, 2014; ISBN 9781107273610.

15. Rokhlin, S. Lamb wave interaction with lap-shear adhesive joints: Theory and experiment. J. Acoust. Soc. Am. 1991, 89, 2758-2765. [CrossRef]

16. Rose, J.L.; Rajana, K.M.; Hansch, M.K.T. Ultrasonic Guided Waves for NDE of Adhesively Bonded Structures. J. Adhes. 1995, 50, 71-82. [CrossRef]

17. Lowe, M.J.S.; Challis, R.E.; Chan, C.W. The transmission of Lamb waves across adhesively bonded lap joints. J. Acoust. Soc. Am. 2000, 107, 1333-1345. [CrossRef] [PubMed]

18. Di Scalea, F.L.; Bonomo, M.; Tuzzeo, D. Ultrasonic guided wave inspection of bonded lap joints: Noncontact method and photoelastic visualization. Res. Nondestruct. Eval. 2001, 13, 153-171. [CrossRef]

19. Ren, B.; Lissenden, C.J. Ultrasonic guided wave inspection of adhesive bonds between composite laminates. Int. J. Adhes. Adhes. 2013, 45, 59-68. [CrossRef]

20. Sherafat, M.H.; Quaegebeur, N.; Lessard, L.; Masson, P.; Hubert, P. Guided Wave Propagation through Composite Bonded Joints. In Proceedings of the EWSHM 7th European Workshop on Structural Health Monitoring, Nantes, France, 10 July 2014.

21. Ren, B.; Lissenden, C.J. Modal content-based damage indicators for disbonds in adhesively bonded composite structures. Struct. Health Monit. Int. J. 2016, 15, 491-504. [CrossRef]

22. Mori, N.; Biwa, S. Transmission of Lamb waves and resonance at an adhesive butt joint of plates. Ultrasonics 2016, 72, 80-88. [CrossRef] [PubMed]

23. Gauthier, C.; El-Kettani, M.; Galy, J.; Predoi, M.; Leduc, D.; Izbicki, J.L. Lamb waves characterization of adhesion levels in aluminum/epoxy bi-layers with different cohesive and adhesive properties. Int. J. Adhes. Adhes. 2017, 74, 15-20. [CrossRef]

24. Mallet, L.; Lee, B.C.; Staszewski, W.J.; Scarpa, F. Structural health monitoring using scanning laser vibrometry: II. Lamb waves for damage detection. Smart Mater. Struct. 2004, 13, 261-269. [CrossRef]

25. Kudela, P.; Wandowski, T.; Malinowski, P.; Ostachowicz, W. Application of scanning laser Doppler vibrometry for delamination detection in composite structures. Opt. Lasers Eng. 2016, 99, 46-57. [CrossRef]

26. Pieczonka, Ł.; Ambroziński, Ł.; Staszewski, W.J.; Barnoncel, D.; Pérès, P. Damage detection in composite panels based on mode-converted Lamb waves sensed using 3D laser scanning vibrometer. Opt. Lasers Eng. 2017, 99, 80-87. [CrossRef]

27. Sunarsa, T.Y.; Aryan, P.; Jeon, I.; Park, B.; Liu, P.; Sohn, H. A reference-free and non-contact method for detecting and imaging damage in adhesive-bonded structures using air-coupled ultrasonic transducers. Materials (Basel) 2017, 10, 1402. [CrossRef]

28. Esfandabadi, Y.K.; De Marchi, L.; Testoni, N.; Marzani, A.; Masetti, G. Full wavefield analysis and Damage imaging through compressive sensing in Lamb wave inspections. IEEE Trans. Ultrason. Ferroelectr. Freq. Control 2017, 65, 269-280. [CrossRef] [PubMed]

29. Dziendzikowski, M.; Dragan, K.; Katunin, A. Localizing impact damage of composite structures with modified RAPID algorithm and non-circular PZT arrays. Arch. Civ. Mech. Eng. 2017, 17, 178-187. [CrossRef]

30. Żak, A.; Radzieński, M.; Krawczuk, M.; Ostachowicz, W. Damage detection strategies based on propagation of guided elastic waves. Smart Mater. Struct. 2012, 21, 35024. [CrossRef]

31. Radzieński, M.; Doliński, Ł.; Krawczuk, M.; Palacz, M. Damage localisation in a stiffened plate structure using a propagating wave. Mech. Syst. Signal Process. 2013, 39, 388-395. [CrossRef]

32. Lee, C.; Park, S. Flaw Imaging Technique for Plate-Like Structures Using Scanning Laser Source Actuation. Shock Vib. 2014, 725030. [CrossRef] 
33. Jothi Saravanan, T.; Gopalakrishnan, N.; Prasad Rao, N. Damage detection in structural element through propagating waves using radially weighted and factored RMS. Meas. J. Int. Meas. Confed. 2015, 73, 520-538. [CrossRef]

34. Geetha, G.K.; Roy Mahapatra, D.; Gopalakrishnan, S.; Hanagud, S. Laser Doppler imaging of delamination in a composite T-joint with remotely located ultrasonic actuators. Compos. Struct. 2016, 147, 197-210. [CrossRef]

35. Marks, R.; Clarke, A.; Featherston, C.; Paget, C.; Pullin, R. Lamb Wave Interaction with Adhesively Bonded Stiffeners and Disbonds Using 3D Vibrometry. Appl. Sci. 2016, 6, 12. [CrossRef]

36. Lee, C.; Zhang, A.; Yu, B.; Park, S. Comparison study between RMS and edge detection image processing algorithms for a pulsed laser UWPI (Ultrasonic wave propagation imaging)-based NDT technique. Sensors (Switzerland) 2017, 17, 1224. [CrossRef] [PubMed]

37. Abràmoff, M.D.; Magalhães, P.J.; Ram, S.J. Image processing with imageJ. Biophotonics Int. 2004, 11, 36-41. [CrossRef]

38. Alleyne, D.N.; Cawley, P. A 2-dimensional Fourier transform method for the quantitative measurement of Lamb modes. In Proceedings of the IEEE Ultrasonics Symposium, Honolulu, HI, USA, 4-7 December 1990; Volume 2, pp. 1143-1146. [CrossRef]

39. Bocchini, P.; Asce, M.; Marzani, A.; Viola, E. Graphical User Interface for Guided Acoustic Waves. J. Comput. Civ. Eng. 2011, 25, 202-210. [CrossRef]

40. Mazzotti, M.; Bartoli, I.; Marzani, A.; Viola, E. A coupled SAFE-2.5D BEM approach for the dispersion analysis of damped leaky guided waves in embedded waveguides of arbitrary cross-section. Ultrasonics 2013, 53, 1227-1241. [CrossRef] [PubMed]

(C) 2018 by the authors. Licensee MDPI, Basel, Switzerland. This article is an open access article distributed under the terms and conditions of the Creative Commons Attribution (CC BY) license (http:/ / creativecommons.org/licenses/by/4.0/). 